\title{
Changes in Fungal Community Structure in Freshwater Canals across a Gradient of Urbanization
}

\author{
Tianma Yuan ${ }^{1}$, Haihan Zhang ${ }^{2}$, Qiaoli Feng ${ }^{1}$, Xiangyu Wu ${ }^{1}$, Yixin Zhang ${ }^{3}{ }^{\oplus}$, Alan J. McCarthy ${ }^{4}$ \\ and Raju Sekar $1, *$ (D) \\ 1 Department of Biological Sciences, Xi'an Jiaotong-Liverpool University, Suzhou 215123, China; \\ Tianma.Yuan@xjtlu.edu.cn (T.Y.); Qiaoli.Feng@xjtlu.edu.cn (Q.F.); Xiangyu.Wu@xjtlu.edu.cn (X.W.) \\ 2 School of Environmental and Municipal Engineering, Xi'an University of Architecture and Technology, \\ Xi'an 710055, China; zhanghaihan@xauat.edu.cn \\ 3 Research Center of Environmental Protection and Ecological Restoration Technology, Department of \\ Landscape Architecture, Gold Mantis School of Architecture, Soochow University, Suzhou 215006, China; \\ yixin.zhang2019@suda.edu.cn \\ 4 Microbiology Research Group, Institute of Integrative Biology, University of Liverpool, \\ Liverpool L69 7ZB, UK; aj55m@liverpool.ac.uk \\ * Correspondence: sekar.raju@xjtlu.edu.cn; Tel.: +86-512-8816-1656
}

Received: 16 May 2020; Accepted: 2 July 2020; Published: 5 July 2020

check for updates

\begin{abstract}
Fungi are an important, yet often, neglected component of the aquatic microflora, and is responsible for primary decomposition and further processing of organic matter. By comparison, the ecological roles of terrestrial fungi have been well-studied, but the diversity and function of fungi that populate aquatic environments remain poorly understood. Here, the impact of urbanization on fungal diversity and community composition in the canal system of Suzhou was assessed by sequencing the internal transcribed spacer 1 (ITS1) region of the rRNA operon. It was amplified from environmental DNA that has been extracted from water samples and pre-deployed decomposing leaves collected from nine sampling locations (high, medium and low urbanization) over two seasons. The fungal diversity and community composition were determined by bioinformatic analysis of the large DNA sequence datasets generated to identify operational taxonomic units (OTUs) for phylogenetic assignment; over 1 million amplicons were sequenced from 36 samples. The alpha-diversity estimates showed high differences in fungal diversity between water and leaf samples, and winter versus summer. Higher numbers of fungal OTUs were identified in both water and leaf samples collected in the summer, and fungal diversity was also generally higher in water than on colonized leaves in both seasons. The fungal community on leaves was usually dominated by Ascomycetes, especially in winter, while water samples contained more diversity at phylum level with Chytridiomycetes often prominent, particularly in summer. At a genus level, a very high relative abundance of Alternaria on leaves was observed in winter at all locations, in contrast to very low abundance of this genus across all water samples. Fungal community composition also varied between sampling locations (i.e., urbanization); in cluster analysis, samples from high urbanization locations formed a distinct cluster, with medium and low urbanization samples clustering together or in some instances, separately. Redundancy analysis shed further light on the relationships between variation in fungal community composition and water physico-chemical properties. Fungal community diversity variation and correlation with different parameters is discussed in detail, but overall, the influence of season outweighed that of urbanization. This study is significant in cataloguing the impact of urbanization on fungal diversity to inform future restoration of urban canal systems on the importance of protecting the natural aquatic fungal flora.
\end{abstract}

Keywords: fungal diversity; urban water; leaf-associated fungi; illumina sequencing; environmental parameters 


\section{Introduction}

Microbial communities comprise a diverse set of bacteria, fungi and archaea, and they all play key roles in micro-food web structure, mediating biogeochemical cycling and transformation of various metals and xenobiotics in aquatic ecosystems [1-3]. Therefore, microbes are fundamental components of freshwater environments and indicators of shifts in ecosystem function [4]. Within microbial communities, a fungal group-aquatic hyphomycetes-plays a key role in colonization of plant litter for degradation in freshwater ecosystems [5,6], important functions in the food web dynamics [7]. Fungi are widely distributed in all biomes and play major roles in organic matter recycling. The description of aquatic hyphomycetes by Ingold in 1942 [8] was decisive in demonstrating that these fungi usually occur, and are abundant, on decaying deciduous leaves in running water [9]. Over 600 fungal species, reported from freshwater, were identified as aquatic hyphomycetes [6]. Although, the ecological roles of terrestrial fungi are relatively well-studied, the diversity and metabolic capabilities of aquatic fungi have been poorly characterized $[10,11]$.

Assessing the structure of freshwater microbial communities is important for evaluating ecosystem functioning $[12,13]$. One of the most regularly used assessments for freshwater microbial communities is leaf bag experiments $[14,15]$, which can be indicative of a number of important biological and ecosystem features. Leaf litter decomposition in streams occurs by physico-chemical interactions, and the action of microorganisms and larger invertebrates [16]. Once leaves enter the water, soluble compounds leach within $24 \mathrm{~h} \mathrm{[17]} \mathrm{and} \mathrm{microbial} \mathrm{conditioning} \mathrm{follow,} \mathrm{whereby} \mathrm{microorganisms}$ colonize and degrade the leaves $[18,19]$. The macroinvertebrates attack the decomposing leaf packs promoting fragmentation [20], and fine meshes, are therefore, used in leaf bag experiments to prevent loss of substrate due to this macroinvertebrate activity [12]. Fungi are considered the main decomposers of leaves by the release of extracellular enzymes [21,22], whereas bacteria are regarded as less important in leaf-litter decomposition $[12,23]$ as they primarily utilize the decomposition products released by fungi $[24,25]$. Aquatic fungi convert refractory leaf litter to more bioavailable nutrients and energy in aquatic food webs [26]. Stream fungi, mainly aquatic hyphomycetes, are impacted by multiple stressors, including temperature, $\mathrm{pH}$, nutrients and toxic chemicals [27]. As fungi degrading leaf litter are more sensitive to disruption than their bacterial counterparts, fungal community analysis provides a good model to evaluate the effects of contaminants on complex ecological systems [28]. A recent global study on leaf-litter fungi in streams emphasized the importance of studying aquatic fungi and suggested that identifying the key environmental drivers (e.g., temperature and ecosystem type) is important to determine the patterns of fungal diversity in aquatic systems $[29,30]$. However, stream ecosystems are vulnerable to different stressors, and litter decomposition could be impacted and illustrated by changes in fungal community structures and activities [31]. For example, anthropogenic stressors associated with urbanization and agriculture could affect microbial assemblages, productivity and activities leading to alteration of decomposition rates [32].

Urbanization is occurring worldwide but at an especially rapid rate in most developing countries. Although, urbanization brings many economic benefits and improves human well-being [33], it can also cause water pollution through the discharge of multiple contaminants including nutrients, endocrine disrupting chemicals, antibiotics and steroid hormones [34,35]. All of these contaminations have major flow-on effects on the ecological condition of waterways in the urban landscape and can lead to loss of biodiversity in freshwater ecosystems [36]. Previous research has shown that the species richness and diversity of the fungal community increased with urbanization in vernal pools of the Cuyahoga River watershed, USA [37]. It has also been reported that when riparian land use changed from natural forest to urban sites with anthropogenically disturbed conditions, fungal richness and biomass were decreased [38]; Afforestation was reported to improve native biodiversity and nutrient cycling to balance the environmental benefits in stream ecosystems [39]. Leaf decomposition in streams is subject to stressors of multiple contaminations [40,41], which could reduce leaf litter breakdown rates with loss of microbial diversity [38]. Complex interactions between nutrients, xenobiotics and global change have been shown to negatively affect the microbial communities associated with leaf 
decomposition in streams [42] and, for example, pesticide toxicity lowered the fungal biomass in decomposed leaves in urbanized watersheds [41]. Community similarity of aquatic hyphomycetes decreased with geographic and latitudinal distance [6]. Also, light pollution, heavy metals and salinization have been found to act as stressors affecting fungal communities and associated leaf litter decomposition $[31,43,44]$. For example, artificial light exposure was shown to enhance the effect of microbial decomposers in conversion of As (III) to As (V). Particularly, artificial light exposure at night changed the fungal community composition and stimulated leaf litter decomposition [44]. $\mathrm{ZnO}$ nanoparticles were shown to have ecotoxicological effects on aquatic fungi, reducing the relative abundance of Anguillospora. Fungal community structure, fungal biomass and enzyme activity were negatively impacted, which caused a significant decrease in freshwater ecosystem function [31]. Salinisation of freshwater depressed microbial respiration, fungal biomass and leaf litter decomposition, and the magnitude of this response was dependent on the ionic composition [43].

Suzhou is a good example of urbanization due to its recent expansion and development, with a long history of a canal system that has rich cultural significance [45]. In recent decades, the canals have faced huge stresses from urbanization, industry, agriculture and aquaculture, and the water quality has deteriorated to cause serious ecological and sanitary problems [46-48]. In our previous study, we reported the impact of urbanization on multiple physico-chemical and microbiological parameters of water quality using Suzhou canals as a model system, and observed significantly higher levels of nutrients, fecal markers and bacterial pathogens in highly urbanized locations [35]. Since fungi play a primary role in leaf litter breakdown in the freshwater ecosystem, the impact of urbanization on fungal diversity and the relationship with multiple environmental parameters was considered worthy of study. In general, studies on the microbiology of freshwater environments pay little attention to the indigenous fungal populations despite their importance in the colonization and degradation of insoluble organic matter inputs. In this paper, the aim is to assess the water and leaf-associated fungal diversity and composition at different sampling sites in Suzhou canals to determine the impact of urbanization, and assess the correlation between multiple environmental parameters (e.g., temperature and nutrients) and fungal diversity or composition. We hypothesized that; (i) urbanization changes the fungal community composition, with high urbanization reducing fungal diversity, and (ii) environmental parameters, such as temperature and nutrients, affect fungal community composition, specifically higher temperature increases fungal diversity and higher nutrient levels decrease fungal diversity. The results of this study will contribute to our knowledge of the natural aquatic fungal flora that needs to be protected in the future restoration of urban canal systems.

\section{Materials and Methods}

\subsection{Sampling Sites}

Nine sampling locations in Suzhou canals were selected for the study, representing three urbanization gradients, High (1-1 to 1-3), Medium (2-1 to 2-3) and Low (3-1 to 3-3) (Figure 1); the urban intensity classification was based on the population density as previously described [35]. Detailed land use types for each sampling location are shown in Figure S1. With reference to the official maps, the detailed land use types were digitized ( $1 \mathrm{~km}$ radii buffer zones) in accordance with the national code for classification of urban land use and planning standards of development land (GB50137-200) [35]. 


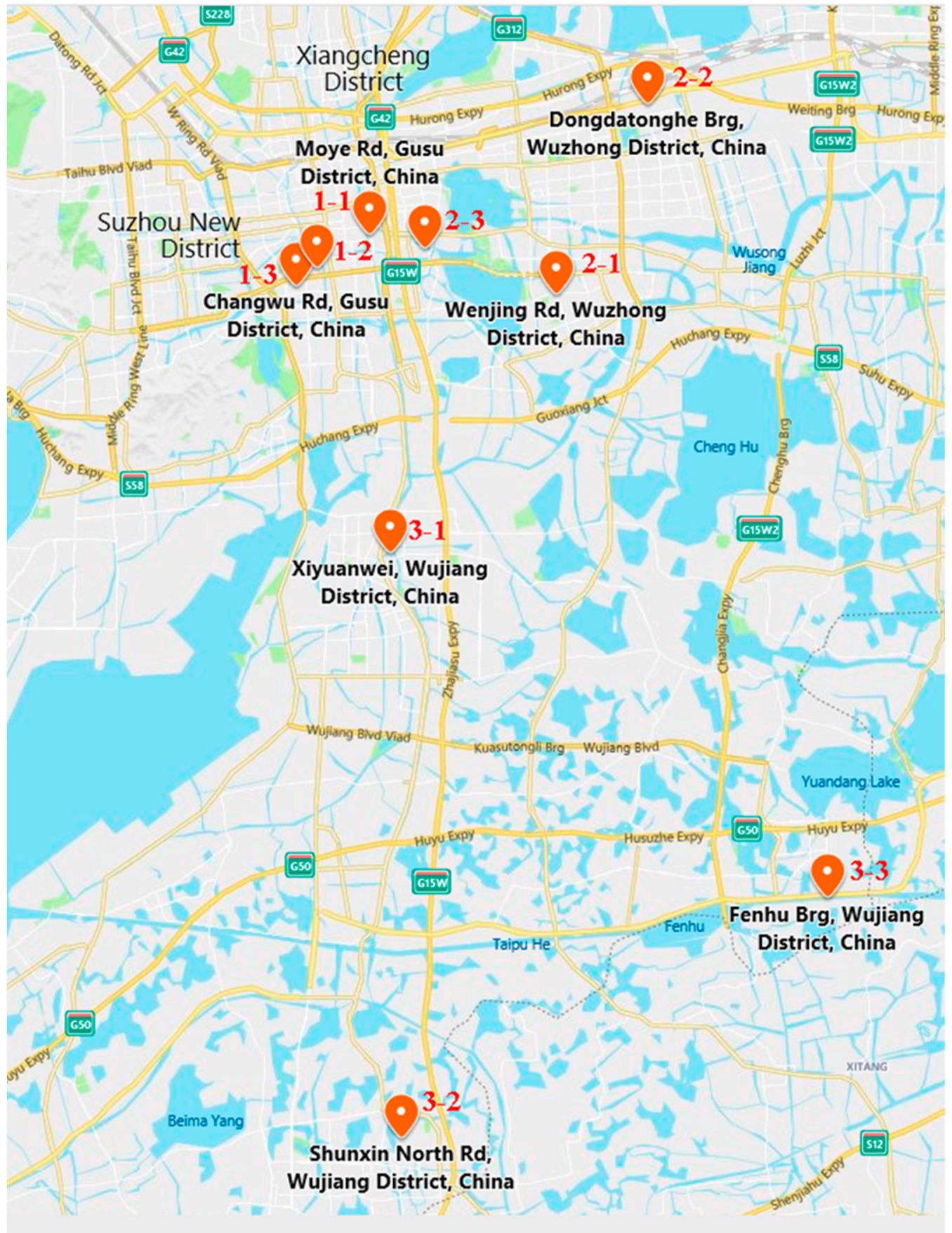

Figure 1. Sampling locations across three urban intensifications (High, Medium, and Low) in Suzhou. 1-1 to 1-3, 2-1 to 2-3 and 3-1 to 3-3 represent High, Medium, and Low urbanization locations, respectively.

\subsection{Field Sampling}

Fresh willow (Salix sp.) leaves were collected from trees lining local canals and oven-dried in the laboratory. Approximately $5 \mathrm{~g}$ of leaves were then placed in a ready-made nylon bag $(15 \times 10 \mathrm{~cm}$, with $0.5-1.0 \mathrm{~mm}$ mesh) to exclude macroinvertebrates while enabling unimpeded microbial colonization and flow through of water. At each location, 6 leaf bags were deployed at the beginning (Day 0) of each sampling campaign. Three leaf bags were collected on Day 14 and 42 from each location for fungal community analysis in both winter and summer in 2015. 
Water samples of $5 \mathrm{~L}$ were collected using sterile containers at each sampling location at the end of the field sampling (Day 42) to characterize multiple nutrients and fungal community composition as described below.

\subsection{Sample Processing and Laboratory Methods}

\subsubsection{DNA Extraction from Water and Leaf Samples}

Water samples of $500 \mathrm{~mL}$ in triplicate were filtered through $0.22 \mu \mathrm{m}$ polycarbonate membrane filters (Millipore, UK). Prior to DNA extraction, membrane filters (water samples) and leaf samples were stored at $-20^{\circ} \mathrm{C}$. Genomic DNA was extracted from membrane filters and leaf samples by using the PowerSoil DNA isolation kit (Mo Bio, Carlsbad, CA, USA) according to the manufacturer's instructions. The membrane filters were cut into small pieces and placed into the PowerBead tubes aseptically and the leaf samples (approximately $0.5 \mathrm{~g}$ ) were ground in liquid nitrogen. The extracted DNA was quantified with a NanoDrop ND $2000{ }^{\circ} \mathrm{C}$ spectrophotometer (Thermo Fisher Scientific, Waltham, MA, USA), then verified by gel electrophoresis and stored at $-20^{\circ} \mathrm{C}$ until further processing.

\subsubsection{Fungal Community Analysis}

The fungal communities in water and leaf samples were profiled by next generation sequencing (NGS) (Illumina MiSeqPE250). Primer sequences (ITS1F 5'-CTTGGTCATTTAGAGGAAGTAA-3' and ITS2R 5'-GCTGCGTTCTTCATCGATGC-3') [49,50] which target the fungal internal transcribed spacer 1 (ITS1) region of the rRNA genes were used to generate amplicon libraries for DNA sequencing.

The PCR reactions were performed in triplicate. The PCR mixture contained $4 \mu \mathrm{L}$ of $5 \times$ FastPfu buffer, $2 \mu \mathrm{L}$ of $2.5 \mathrm{mM}$ dNTPs, $0.8 \mu \mathrm{L}$ of each primer $(5 \mu \mathrm{M}), 0.4 \mu \mathrm{L}$ of FastPfu Polymerase, $0.2 \mu \mathrm{L}$ of BSA, $10 \mathrm{ng}$ of template DNA and $\mathrm{ddH}_{2} \mathrm{O}$ to $20 \mu \mathrm{L}$. The PCR cycling conditions were: $95^{\circ} \mathrm{C}$ for $3 \mathrm{~min}$, followed by 27 cycles at $95{ }^{\circ} \mathrm{C}$ for $30 \mathrm{~s}, 55{ }^{\circ} \mathrm{C}$ for $30 \mathrm{~s}$, and $72{ }^{\circ} \mathrm{C}$ for $45 \mathrm{~s}$ and a final extension at $72{ }^{\circ} \mathrm{C}$ for $10 \mathrm{~min}$. The PCR amplified products were extracted and purified using the AxyPrep DNA extraction kit and sequenced using the Illumina MiSeq platform according to the standard protocols. The sequencing and the preliminary data analyses were carried out by Majorbio Pharmaceutical Technology Ltd., Shanghai, China. The sequences were analyzed using the Fungal High-throughput Taxonomic Identification tool for use with Next-Generation Sequencing (FHiTINGS) databases [51,52], and operational taxonomic units (OTUs) were clustered at $97 \%$ similarity cut-off. The phylogenetic affiliations (phylum, order, and genus levels) and further analyses were performed to compare the taxonomic structure of fungal communities in water and leaf samples collected from different urban gradients and seasons. The ITS1 sequences obtained were submitted to the National Center for Biotechnological Information (NCBI) Short Read Archive (SRA) database under the accession numbers SAMN10688512 to SAMN10688547.

\subsubsection{Physico-Chemical Analyses of Water Samples}

Water temperature (WT) was measured during the field sampling and multiple water quality parameters including total nitrogen (TN), total phosphorous $(\mathrm{TP})$, nitrate- $\mathrm{N}\left(\mathrm{NO}_{3}-\mathrm{N}\right)$, nitrite- $\mathrm{N}\left(\mathrm{NO}_{2}-\mathrm{N}\right)$, ammonium nitrogen $\left(\mathrm{NH}_{4}-\mathrm{N}\right)$, phosphate $\left(\mathrm{PO}_{4}-\mathrm{P}\right)$, total organic carbon (TOC) and Chlorophyll $a$ $(\mathrm{Chl} a)$ were analysed in the laboratory after sample processing as described previously $[35,53]$.

\subsection{Statistical Analyses}

The fungal diversity and richness within each sample (alpha diversity) was measured by Shannon and Simpson diversity indices, abundance-based coverage estimator (ACE) and Chao1 richness estimator [54]. The variations in the diversity between samples (beta diversity) were studied by Non-Metric Multidimensional Scaling Analysis (NMDS) and cluster analysis. The relationships between fungal diversity and the environmental parameters (e.g., temperature and multiple nutrients) were addressed by redundancy analysis (RDA) [55] and the production of heat maps [56]. All the 
above analyses were carried out using the $R$ statistics software package. The physico-chemical data for water samples were analysed by two-way analysis of variance (ANOVA) with "IBM SPSS Statistics" to identify variations in relation to season and urban intensification.

\section{Results}

\subsection{Fungal Diversity and Community Composition in Water and Leaf Samples}

The ITS1 amplicon libraries from 36 representative samples (12 water samples and 24 leaf samples) collected from different urbanization gradients in Suzhou were sequenced. In total, 1,065,600 reads were obtained from water and leaf samples, and the sequencing data were normalized to 29,600 reads per sample. The rarefaction curves based on the number of OTUs with normalized reads are shown in Figure S2. High Good's coverage values (0.993-0.999) (Table 1) were obtained for all the water and leaf samples, which indicated that the sequencing depths were sufficient for reliable community analysis [57]. In general, the number of OTUs were higher in summer samples, and higher in water versus colonized leaf samples; this trend is also apparent in the Shannon diversity and other alpha diversity indices (Table 1).

Table 1. Similarity-based OTUs and species richness and diversity estimates (Mean \pm SD) for fungal community in water and leaf samples collected from different urban gradients (High, Medium, and Low) in winter and summer 2015. (The number of reads was normalized to 29,600 per sample).

\begin{tabular}{lcccccc}
\hline Sample Group & OTUs & ACE & Chao1 $^{\mathbf{2}}$ & Shannon $^{3}$ & Simpson $^{\mathbf{4}}$ & Coverage $^{\mathbf{5}}$ \\
\hline WI, W, HU & $439 \pm 81$ & $572 \pm 33$ & $560 \pm 54$ & $3.66 \pm 0.41$ & $0.060 \pm 0.025$ & $0.996 \pm 0.000$ \\
WI, W, MU & $206 \pm 52$ & $286 \pm 83$ & $269 \pm 70$ & $1.26 \pm 0.01$ & $0.519 \pm 0.057$ & $0.998 \pm 0.001$ \\
WI, W, LU & $539 \pm 286$ & $663 \pm 296$ & $664 \pm 280$ & $2.94 \pm 1.11$ & $0.230 \pm 0.168$ & $0.995 \pm 0.001$ \\
SU, W, HU & $1063 \pm 69$ & $1128 \pm 54$ & $1128 \pm 64$ & $5.29 \pm 0.25$ & $0.014 \pm 0.005$ & $0.995 \pm 0.001$ \\
SU, W, MU & $919 \pm 142$ & $999 \pm 122$ & $991 \pm 127$ & $4.60 \pm 0.32$ & $0.050 \pm 0.020$ & $0.995 \pm 0.000$ \\
SU, W, LU & $798 \pm 215$ & $917 \pm 144$ & $905 \pm 141$ & $4.00 \pm 0.92$ & $0.093 \pm 0.067$ & $0.995 \pm 0.001$ \\
WI, L, HU & $482 \pm 123$ & $638 \pm 147$ & $616 \pm 149$ & $3.41 \pm 0.43$ & $0.097 \pm 0.044$ & $0.995 \pm 0.001$ \\
WI, L, MU & $69 \pm 15$ & $125 \pm 55$ & $109 \pm 37$ & $1.02 \pm 0.26$ & $0.438 \pm 0.059$ & $0.999 \pm 0.000$ \\
WI, L, LU & $99 \pm 27$ & $223 \pm 84$ & $158 \pm 44$ & $1.45 \pm 0.22$ & $0.374 \pm 0.109$ & $0.999 \pm 0.000$ \\
SU, L, HU & $621 \pm 339$ & $870 \pm 316$ & $797 \pm 324$ & $2.65 \pm 1.29$ & $0.265 \pm 0.148$ & $0.994 \pm 0.003$ \\
SU, L, MU & $628 \pm 323$ & $933 \pm 204$ & $814 \pm 272$ & $2.85 \pm 1.07$ & $0.209 \pm 0.122$ & $0.993 \pm 0.002$ \\
SU, L, LU & $544 \pm 323$ & $765 \pm 348$ & $723 \pm 373$ & $3.27 \pm 0.95$ & $0.104 \pm 0.055$ & $0.994 \pm 0.003$
\end{tabular}

${ }^{1}$ ACE: Abundance Coverage-based Estimator of richness; ${ }^{2}$ Chao1 richness estimates; ${ }^{3}$ Shannon diversity index; ${ }^{4}$ Simpson diversity index; ${ }^{5}$ Coverage: Good's coverage.; WI-Winter; SU-Summer; W-Water; L-Leaf; HU-High urban; MU—Medium urban; LU—Low urban.

The sequence datasets were further analyzed at phylum, order, and genus levels (Figures 2-4). The fungal community in water samples was quite different from the community in leaf samples, and there were obvious seasonal differences. At phylum level, members of the Ascomycota were dominant in most leaf samples, particularly those collected in winter. In water samples, there were distinctions in community composition between high, medium and low urbanization locations, with dominance of Glomeromycota (53-71\%), Chytridiomycota (67-81\%) and Ascomycota (45-81\%) recorded in those locations, respectively. In water and leaf samples collected in summer, Ascomycota (6-98\%) and Chytridiomycota (2-65\%) were dominant but there was no clear pattern that distinguished the water and leaf samples, or between locations (Figure 2).

At order level, the fungal community composition showed clear differences between water and leaf samples. Urbanization status and season (summer versus winter) also impacted the community structure in the water samples (Figure 3). In winter, members of Archaeosporales (37-57\%), Rhizophydiales (65-77\%) and Pezizales (29-77\%) were dominant in water samples collected from high, medium, and low urbanization locations, respectively. In summer, members of Rhizophydiales were dominant (8-44\%) in most water samples. The fungal community composition of leaf samples collected in both winter and summer varied with urbanization. Pleosporales was dominant (6-99\%) in most leaf samples collected in winter, especially in the leaf samples, collected from medium (84-99\%) and low 
(55-86\%) urbanization locations. In summer, Diversisporales was represented at a relatively higher percentage (1-57\%) in most leaf samples (Figure 3).

(A)

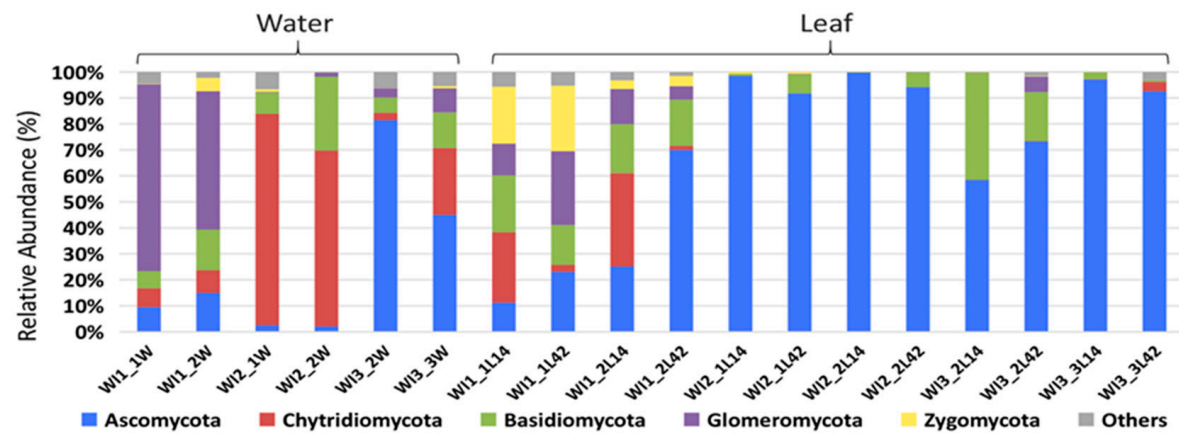

(B)

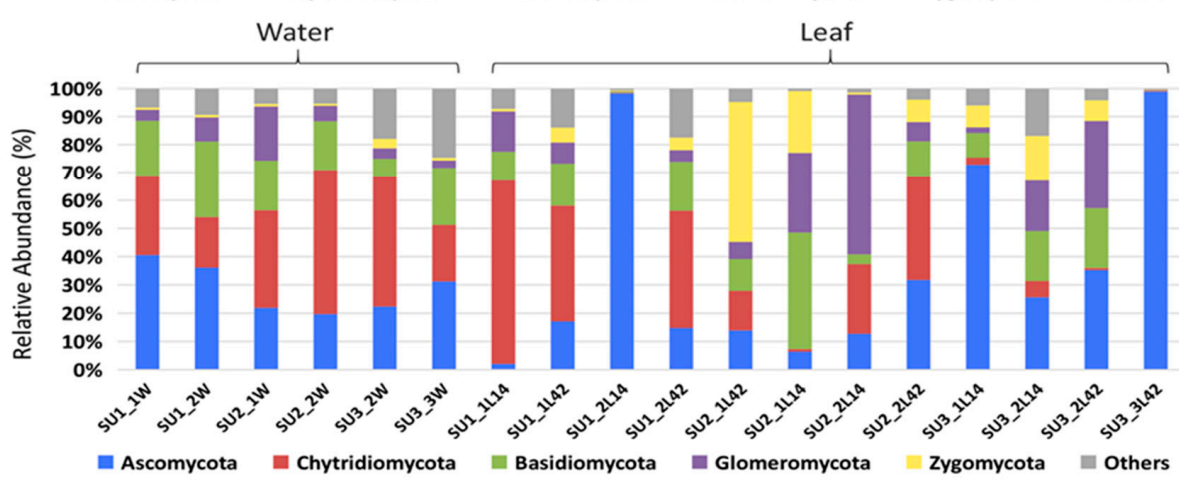

Figure 2. Relative abundance of fungal phyla in water and leaf samples collected from different locations in winter (A) and summer (B). (WI = Winter; SU = Summer; 1-1 to 3-3 = Sampling locations in high to low urban gradients, respectively; $\mathrm{W}=$ Water samples; L14 and L42 = Leaf samples collected on 14th and 42nd day, respectively).

(A)

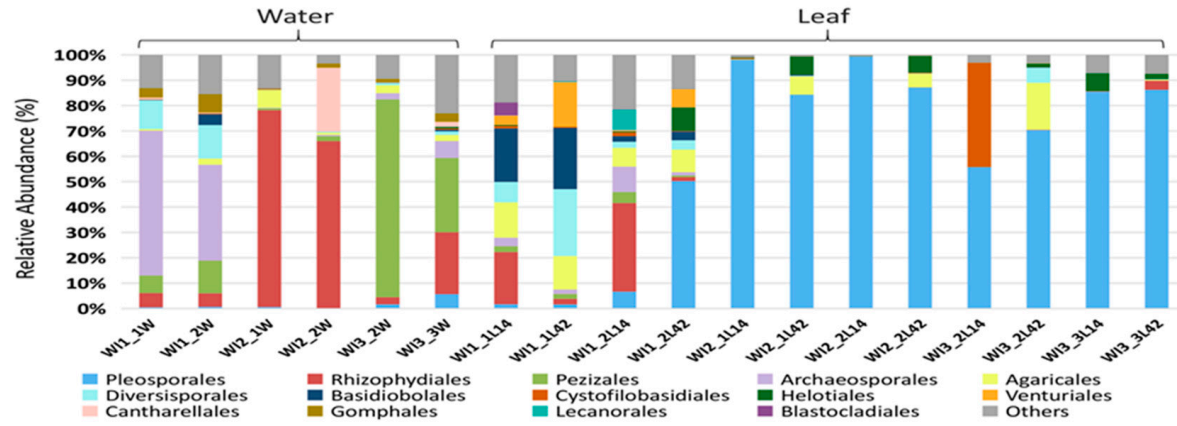

(B)

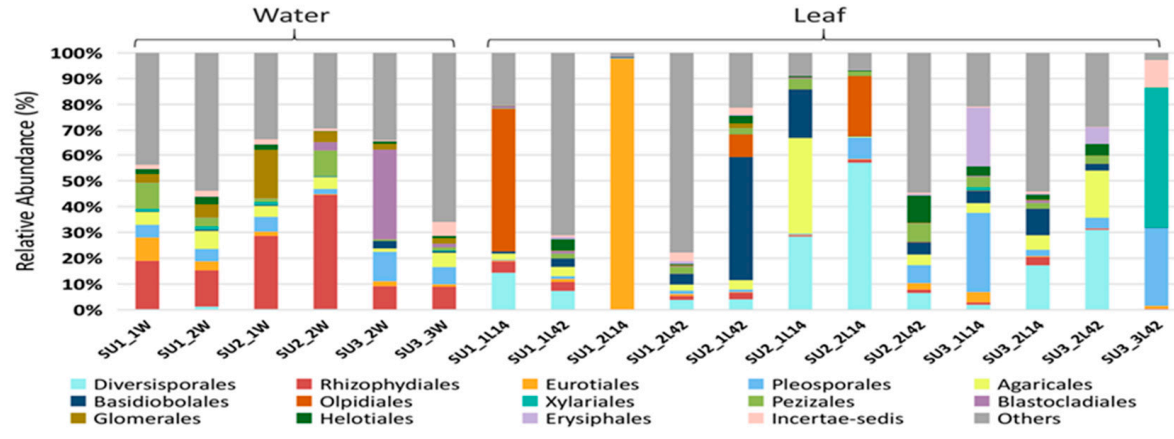

Figure 3. Relative abundance of fungal orders in water and leaf samples collected from different locations in winter (A) and summer (B). (WI = Winter; SU = Summer; 1-1 to 3-3 = Sampling locations in high to low urban gradients, respectively; $\mathrm{W}=$ Water samples; L14 and L42 = Leaf samples collected on 14th and 42nd day, respectively). 


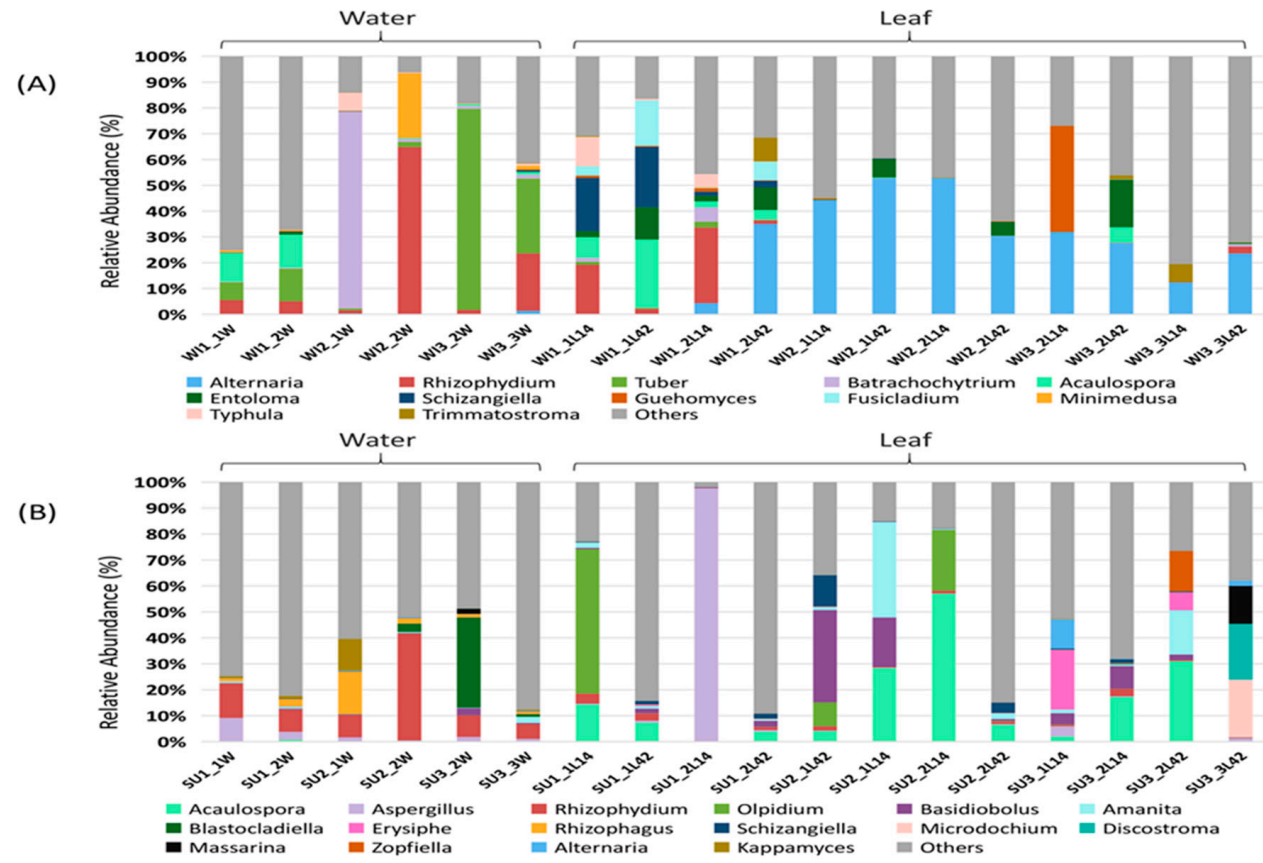

Figure 4. Relative abundance of fungal genera in water and leaf samples collected from different locations in winter (A) and summer (B). (WI = Winter; SU = Summer; 1-1 to 3-3 = Sampling locations in high to low urban gradients, respectively; $\mathrm{W}=$ Water samples; L14 and L42 = Leaf samples collected on 14th and 42nd day, respectively).

At genus level, Alternaria was dominant in most leaf samples, especially in the samples collected from medium and low urbanization locations (Figure 4). In water samples, the fungal community varied between locations (urbanization) and seasons, however extremely low $(<2 \%)$ relative abundance of Alternaria was observed in most samples (Figure 4).

\subsection{Comparison of Fungal Communities of Water and Colonized Leaves and the Impact of Urbanization}

Venn diagram analysis was performed to identify the extent of overlap in fungal OTU composition between water and leaf samples collected from different sampling locations in winter and summer. The number of unique OTUs overall was higher in water samples (1796) than leaf samples (1165) (Figure 5A); the number of the unique OTUs in the samples collected in summer was extremely high (2988) as compared to winter (617), with shared OTUs comprising 1060 (Figure 5B).

In relation to the impact of urbanization on fungal community composition in water samples collected in winter (Figure 5C), there were much fewer unique OTUs in the medium urbanization locations (77) compared to low (396) and high (235) urbanization locations. However, in leaf samples (Figure 5D), there were a great many more unique OTUs in samples collected from locations with high (751) urbanization compared to medium (26) and low (55) urbanization. In both water and colonised leaf samples, collected in summer, the numbers of unique OTUs were relatively comparable across all three levels of urbanization (Figure 5E,F).

The cluster analysis, presented in Figure 6, demonstrates that degree of urbanization was the primary driver of variation in fungal community composition. Most of the water or colonized leaf samples collected from the highly urbanized locations (1-1 and 1-2) formed a separate cluster (Figure 6); leaf samples collected from medium (2-1 and 2-2) and low urbanization locations (3-1 to 3-3) in winter also formed separate clusters (Figure 6B). Similarly, water samples collected from medium (2-1 and 2-2) and low urbanization locations (3-1 to 3-3) in summer formed separate clusters (Figure 6C). Overall, the clustering observed was based on the type of samples (water or colonized leaves) and degree of urbanization (low, medium, high). The NMDS analysis (Figure 7) also showed similar patterns in that the samples collected from high urbanization locations (1-1 and 1-2) in winter were usually clustered 
separately (Figure 7), but for water samples collected in summer (Figure 7C), the samples from high (1-1 and 1-2) and medium (2-1 and 2-2) urbanization locations were clustered together.

(A)

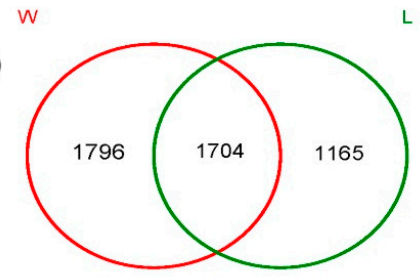

(C)

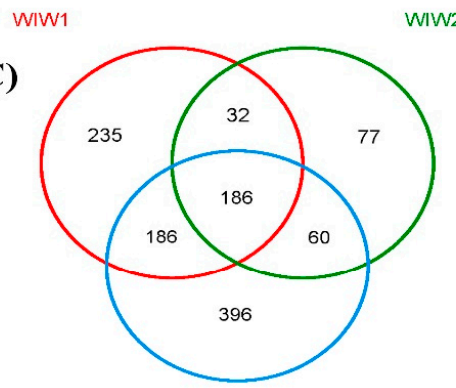

WIW3

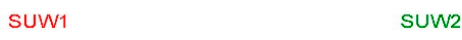

(E)

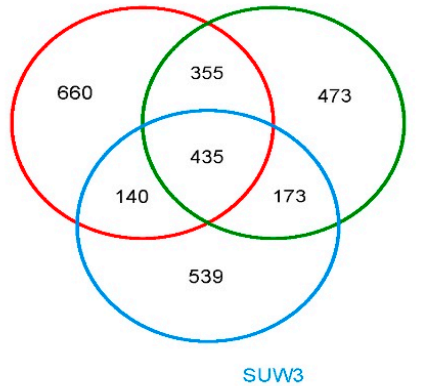

(B)

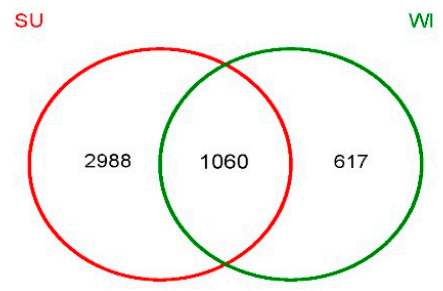

(D)

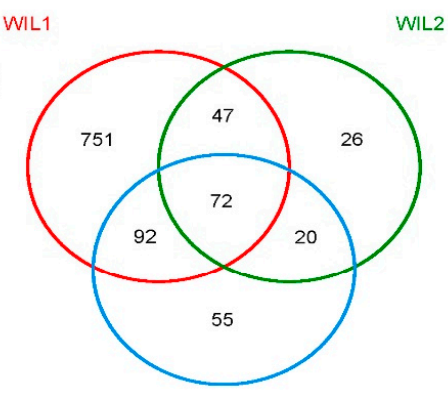

WL3

(F)

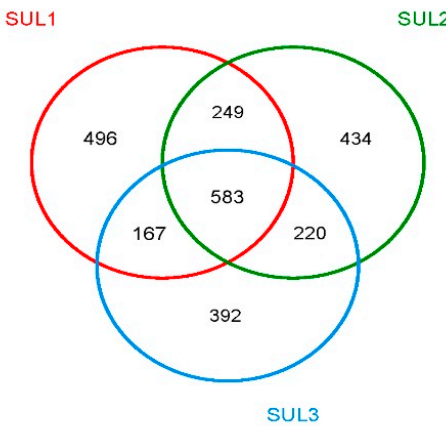

Figure 5. Venn diagrams showing unique and shared fungal OTUs in the amplicon sequence libraries compared between water and leaf samples (A), and between different sampling locations in winter and summer $(\mathbf{B}-\mathbf{F})$. ( $\mathrm{W}=$ Water; $\mathrm{L}=$ Leaf; WI = Winter; $\mathrm{SU}=$ Summer; WIW = Winter Water; WIL = Winter Leaf; SUW = Summer Water; SUL = Summer Leaf; 1,2,3 = High, Medium and Low urbanization locations, respectively).

Redundancy analysis (RDA) was carried out to investigate the relationship between environmental parameters (particularly temperature and multiple nutrients) and fungal community composition in water and leaf samples in winter and summer (Figure S3). The RDA1 and RDA2 explained 98\% and $1.6 \%$ of variations observed, respectively in fungal community in water samples collected in winter (Figure S3A). In particular, the nutrients (TN, TP and $\mathrm{NH}_{4}-\mathrm{N}$ ) influenced the fungal community composition in high urbanization locations (1-1 and 1-2) and one of the low urbanization locations (3-3). In the colonised leaf samples collected in winter, (Figure S3B), the RDA1 and RDA2 explained 62\%, and $12 \%$ of the total variation in the fungal community, respectively and parameters, such as TN, TP, $\mathrm{NO}_{3}-\mathrm{N}, \mathrm{NO}_{2}-\mathrm{N}$ and $\mathrm{NH}_{4}-\mathrm{N}$ were found to be major factors influencing the community composition in high urbanization locations (1-1 and 1-2). The RDA biplot pattern was similar for water samples collected in summer (Figure S3C), in which the RDA1 and RDA2 explained $53 \%$ and $25 \%$ of the total variations observed in the fungal community, and nutrient parameters ( $\mathrm{TN}, \mathrm{TP}$ and $\mathrm{NH}_{4}-\mathrm{N}$ ) affected the community composition in the high urbanization locations (1-1 and 1-2) and one medium urbanization location (2-1). In leaf samples, RDA1 and RDA2 explained $54 \%$ and $11 \%$ of the variation in the 
fungal community, respectively and nutrients (TN, TP, $\mathrm{NH}_{4}-\mathrm{N}$ and $\left.\mathrm{PO}_{4}-\mathrm{P}\right)$ influenced the community composition in one of the high urbanization locations (1-2) (Figure S3D). The overall RDA analysis results indicated that the nutrient parameters were key factors, influencing the fungal community composition in water and leaf samples, collected from different urban gradients.

(A)

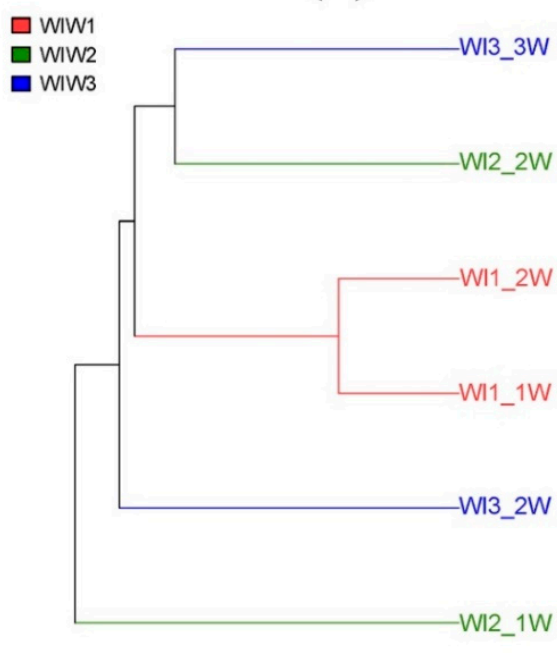

0.01

(C)

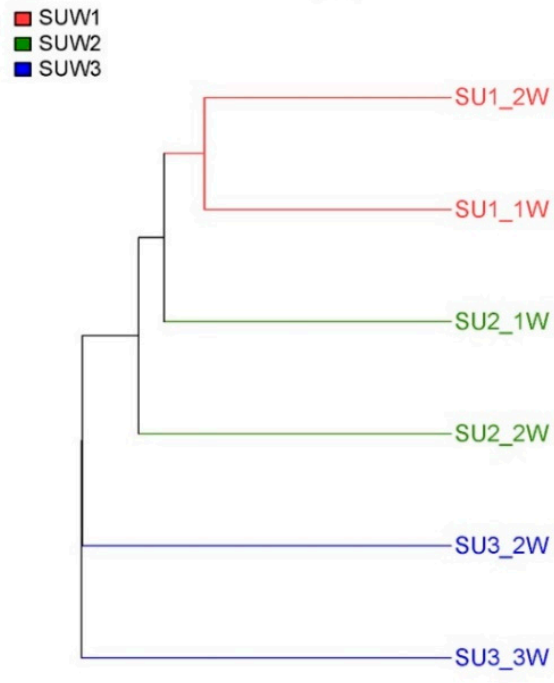

0.01
(B)

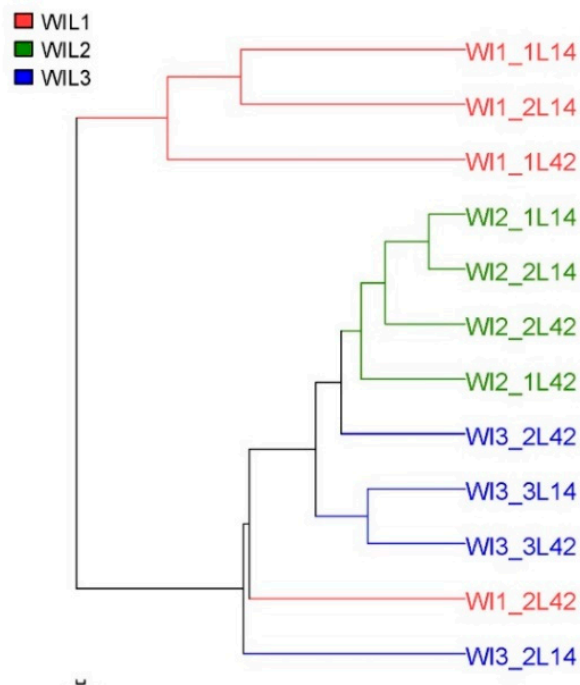

(D)

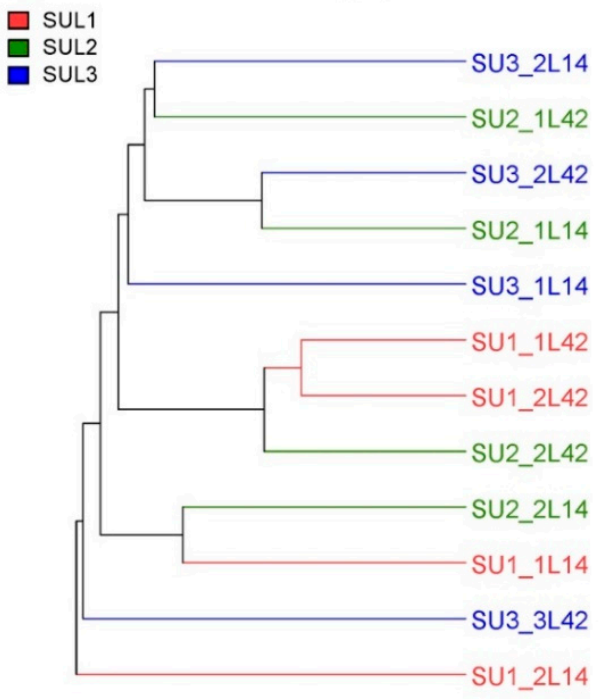

0.01

Figure 6. Cluster analysis showing the similarity in fungal diversity in water and leaf samples collected from sampling locations across the urbanization gradient in winter and summer. Comparison of fungal diversity in water $(\mathbf{A}, \mathbf{C})$ and leaf $(\mathbf{B}, \mathbf{D})$ samples collected in winter $(\mathbf{A}, \mathbf{B})$ and summer $(\mathbf{C}, \mathbf{D})$. $($ WIW = Winter Water; WIL = Winter Leaf; SUW = Summer Water; SUL = Summer Leaf; 1,2,3 = High, Medium, and Low urbanization, respectively). 

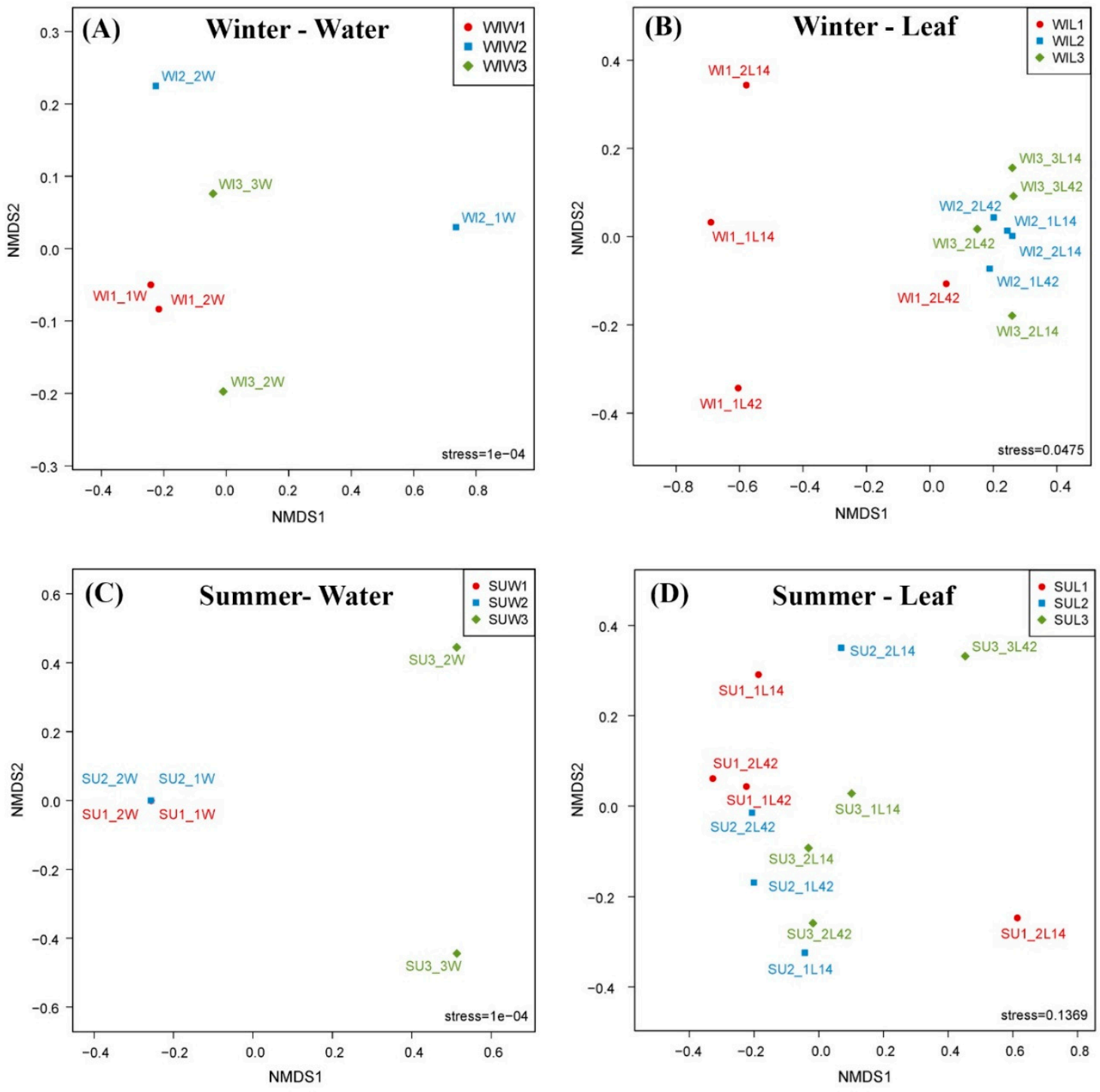

Figure 7. Visualization of fungal beta-diversity among water and leaf samples collected from different locations in winter and summer by non-metric multidimensional scaling (NMDS) analysis. $(\mathbf{A}, \mathbf{C})$ - Water samples collected from different sampling locations in winter, and summer, respectively (B,D)_Leaf samples collected from different sampling locations in winter and summer, respectively; WIW = Winter Water; WIL = Winter Leaf; SUW = Summer Water; SUL = Summer Leaf; 1,2,3 = High, Medium, and Low urbanization locations, respectively).

The relationship between fungal community and environmental parameters (temperature and nutrients) (Table S1) was further examined by producing heat maps for all the water and leaf samples collected (Figure 8). The heat map for water samples collected in winter (Figure 8A) indicated that temperature was the main driver of the relative abundance of ten fungal genera, Acaulospora, Trichosporon, Massarina, Cryptococcus, Scutellospora, Bassidiobolus, Laetiporus, Paraglomus, Dendryphion and Morchella; higher concentrations of nutrients drove the relative abundance of the genera Clydaea, Fomitopsis, Ramaria and Glomus, while lower concentrations of nutrients influenced the relative abundance of genera Calostoma, Leptosphaerulina, Blumeria, Batrachochytrium and Trphula. The driver of high/low temperature versus higher/lower concentrations of nutrients on the relative abundance of several fungal genera was also observed in leaf samples collected in winter (Figure 8B), and in both water and leaf samples collected in summer (Figure 8C,D). 

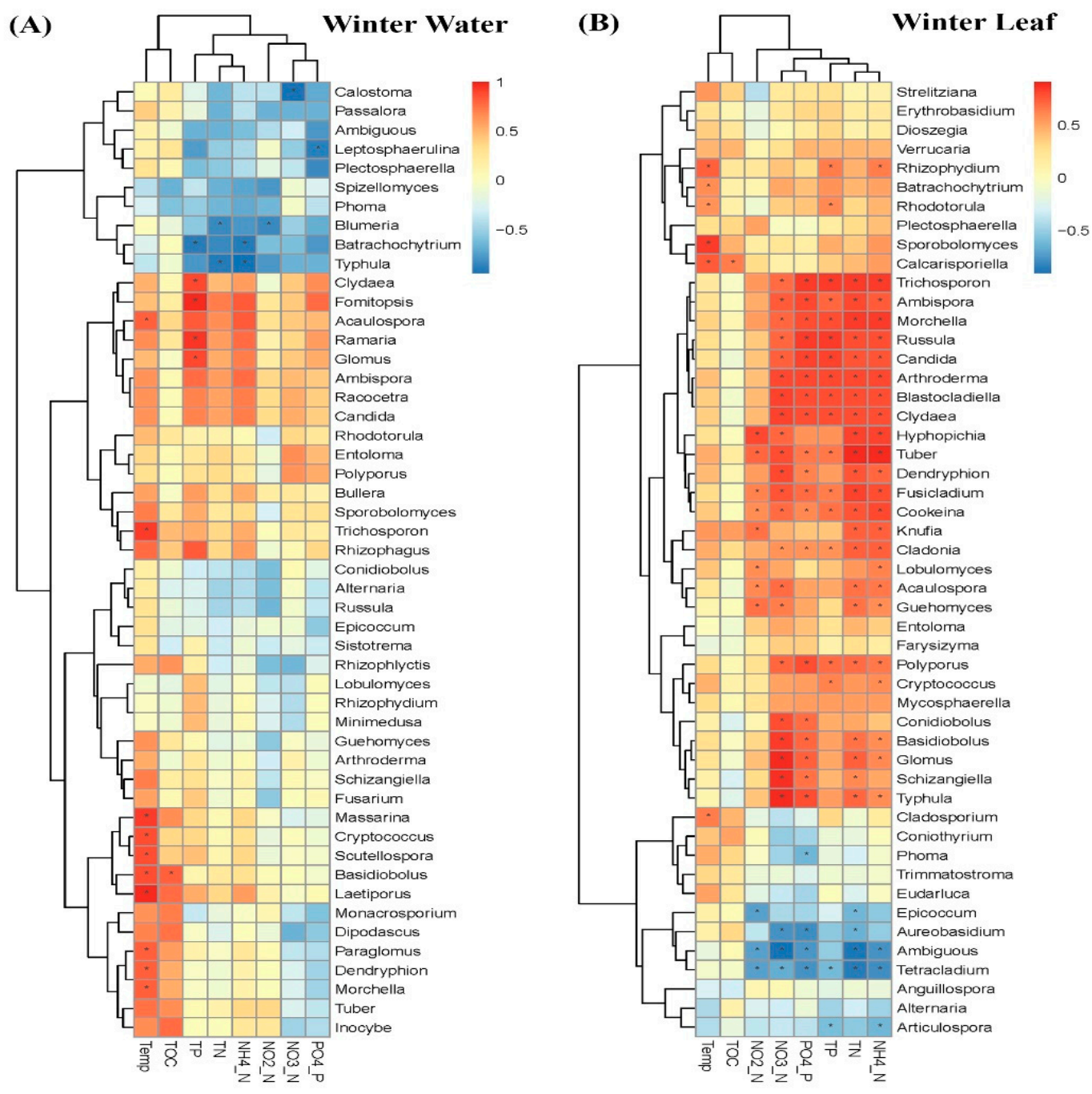

Figure 8. Cont. 

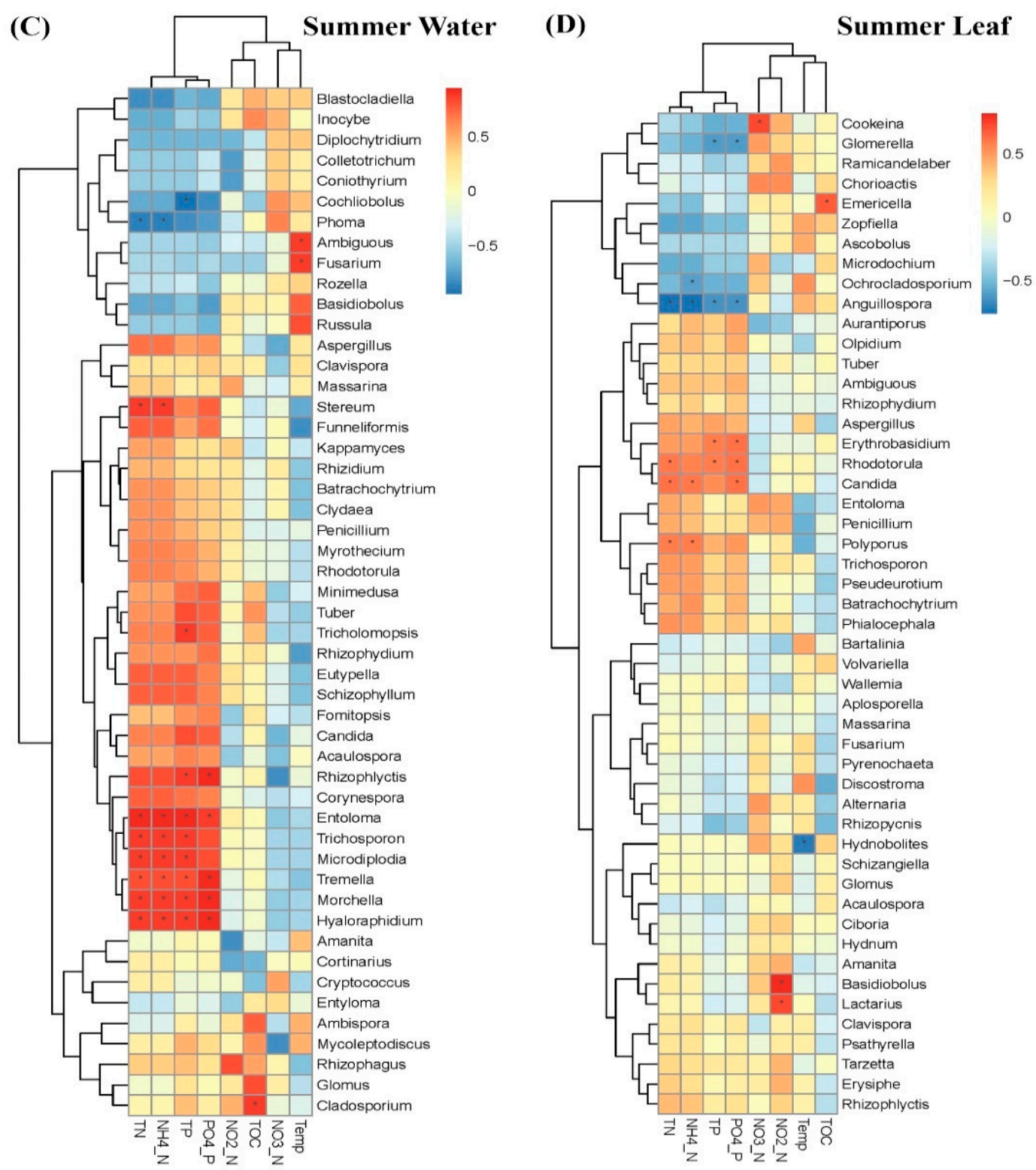

Figure 8. Clustered heat maps showing the relationship between the relative abundance of different fungal genera and environmental parameters. (A) Water samples; (B) Leaf samples collected in winter; (C) Water samples; and (D) Leaf samples collected in Summer.

\section{Discussion}

The results from this study show that fungal diversity and composition in Suzhou canals was affected by both season (water temperature) and urbanization (variations in nutrients and land use), with the former more profound, and these findings support our hypotheses. Urbanization altered the fungal community composition in canal water and colonizing suspended insoluble organic matter (leaves). However, urbanization did not reduce fungal diversity as expected. Environmental drivers (temperature and nutrients) affected the fungal composition; higher temperature during summer increased fungal diversity, whereas higher levels of nutrients (eutrophication) associated with urbanization did not reduce fungal diversity. The identification and distribution of fungal OTUs in the datasets presented here demonstrated seasonal patterns, which indicated that temperature is a key factor that affects fungal composition in both water and colonized leaf material. This observation of increased fungal diversity at higher temperatures (summer) is consistent with a recent study in the tropical Tietê 
River (Brazil) in which it was reported that aquatic fungal communities were affected by seasonality [58]. Although in the Tietê River, there was a large turn-over of the aquatic fungal community in two seasons, only a small percentage of taxa $(11 \%)$ were shared in both seasons. Temperature was a key factor impacting on water density and causing stratification of the water body, leading to increased availability of nutrients on the warmer surface, and then affecting the aquatic fungal community composition [58]. In another study conducted in Natori River in Japan, the taxonomic composition and richness of epilithic fungal communities varied along the longitudinal gradient of the river and the variation was found to be dependent on the water temperature, with taxonomic richness increasing in the warm water season [59]. In boreal streams located in south-central Sweden, the structure of leaf-litter-associated fungal communities was influenced by seasonality, and temperature had a more profound effect on fungi (fungal community structure) than bacteria (bacterial community structure) [60]. The effects of experimental and seasonal warming on leaf litter decomposition and associated fungal biomass and sporulation rates of aquatic hyphomycetes were assessed in different seasons in a mountain stream in Central Portugal [61]. The study observed that experimental warming of stream water stimulated litter decomposition in winter only, and there were no effects found on fungal biomass and sporulation rate of aquatic hyphomycetes [62]. Field studies in headwater streams in the Montagne Noire (southwest of France), and associated microcosm experiments, indicated that higher temperature increased the microbial processes exponentially [63]. In microcosms, under different temperature regimes, the loss of certain species could lead to measurable losses in ecological functions of fungal assemblages, and faster leaf decomposition was observed when the temperature was increased from 16 to $24^{\circ} \mathrm{C}$ [30]. The optimal temperature for aquatic fungal diversity, its abundance and activity generally range between $15-25^{\circ} \mathrm{C}$. Although, some fungal species live in hot Sulphur springs, fungal diversity is very restricted at temperatures over $35^{\circ} \mathrm{C}$ [64]. In our study, the ranges of water temperature in winter and summer were $6.5-11{ }^{\circ} \mathrm{C}$, and $26-31{ }^{\circ} \mathrm{C}$, respectively (Table S1). Therefore, increased fungal diversity, due to higher temperatures in suitable ranges, reported here, aligns with some of the previous studies focused on freshwater systems.

In addition to the seasonal effect on fungal diversity (summer versus winter), the degree of urbanization (low, medium, or high) was shown to impact on fungal community in both, water and on colonized leaves, and at different taxonomic levels. Fungal community structure on colonized leaves was predictably quite different from that in free water in the canals. At phylum, order and genus levels, the water associated fungal community had distinct compositions between high, medium and low urbanization locations, although for the leaf associated fungal community this effect was only marked at the level of genus diversity. Our use of urbanization levels, in this study design, is analogous to an investigation of streams impacted by anthropogenic activities such as land-use disturbance where decreased fungal diversity and impaired ecosystem functions were observed [65]. In contrast, decreased fungal diversity at higher levels of urbanization in the Suzhou canal system was not observed in our study. A study focused on the influence of habitat area and stress on the soil microbes in Manhattan (NYC) showed some tendency toward the loss of fungal diversity with decreases in habitat size and increases in stress, but no significant variations in fungal composition or richness between habitats or sites; microbial diversity and composition appeared less sensitive to habitant patchiness and urban stress, as compared to macroorganisms [66]. A field study conducted in five streams along the Ava River basin in the Northwest of Portugal also indicated that fungal diversity increased with moderate eutrophication, but decreased at increasing eutrophication with high levels of nutrients [5]. All these findings support the results observed in our study.

The phyla Ascomycota and Chytridiomycota were detected in many water and leaf samples although their percentage composition varied between seasons and sampling locations (i.e., urbanization). These two phyla are ubiquitous in nature and are major components of the aquatic fungal community playing important roles in freshwater ecosystems [10,64]. Ascomycota is the largest phylum in the fungi and have been found to be dominant in various habitats. A recent global study on the diversity of leaf litter fungi indicated that the community was dominated by members of 
the phylum Ascomycota [29]. It was also reported that Ascomycota was the dominant phylum for oak-litter decomposition in five streams along the Ava River basin in the Northwest of Portugal, and its relative abundance decreased in the most eutrophic streams [5]. Analysis of environmental DNA samples has identified, taxa belonging to Ascomycota, Chytridiomycota, Basidiomycota, Oomycota and Zygomycota on decomposing leaves $[67,68]$. Chytrids play multiple roles in freshwater systems-as a food source for zooplankton, in decomposition of organic matter, in addition to parasitic activity on plants and animals. In particular, they are reported to decompose complex organic molecules such as chitin, cellulose, protein and other detritus components [69] and have been found as the predominant fungal group in lakes of North-East Germany [70]. Chytridiomycota is well represented in streams, especially if eutrophic [5]. At order level, members of Archaeosporales (Glomeromycota), Rhizophydiales (Chytridomycota) and Pezizales (Ascomycota) were dominant in water at high, medium, and low urbanization locations, respectively during winter whereas in summer, members of Rhizophydiales were dominant. In leaf samples, Pleosporales (Ascomycota) was dominant in medium and low urbanization locations in winter, whereas Diversisporales (Glomeromycota) predominated in summer. The major species within Pleosporales are saprobes on decaying plant material in freshwater [71] and the data presented here are consistent with previous studies [70,72], in which Rhizophydiales, Pleosporales and Pezizales were commonly observed fungal orders in the freshwater systems. At genus level, members of Alternaria were represented at high percentages in most leaf samples collected from medium and low urbanization locations in Suzhou in winter. Alternaria is ubiquitous in the environment and is a natural part of the fungal flora of soil and water [73]. Moreover, members of Alternaria are involved in decay and decomposition [74] and some species are phytopathogens that cause plant diseases [75], which explains their high relative abundance in colonized leaf samples collected from medium and low urbanization locations as there were more riparian forest, agricultural land and public green land at these locations. Alternaria has also been found to grow well at low temperatures and spoil vegetables and fruits stored in refrigerators [75]. This correlates with representation of Alternaria in high percentages in leaf samples in winter. However, Alternaria were represented at lower percentages in colonized leaves collected from high urbanization locations. Clear changes in fungal community between sampling locations (urbanization) were observed at phylum and order levels, but became masked by complexity, and were indiscernible at genus level. Fungal community structure variation between sampling locations can be correlated with differences in water quality and also the land use pattern. As shown in Figure S1, the land use pattern was distinct between the three urban classifications and in our previous study [35], we showed that urbanization influences the water quality, and also the presence and abundance of fecal markers and bacterial pathogens. The results obtained in this study reinforce the impact of urbanization on aquatic microbiology of the Suzhou canal system by demonstrating that the diversity and composition of fungal communities is similarly influenced. Beta diversity analysis (cluster analysis and NMDS) revealed variations in fungal community structure in both water and colonized leaf samples across sampling locations (urbanization). A recent report showed that fungal biomass in leaves was lower in urbanized watersheds than in forested watersheds [41], and further supported the general conclusion that aquatic fungal communities are influenced by urbanization.

The relationship between fungal community and physico-chemical water properties analyzed by heat maps and RDA showed that the nutrient parameters and the temperature (seasons) influenced fungal community composition, in line with previous studies in other aquatic systems. Fungicide and nutrients at enriched concentrations acted as stressors affecting the microbial diversity in streams [76] and the dynamics of aquatic fungal communities in a heavily-contaminated tropical river were found to be mainly driven by multiple physico-chemical parameters, such as $\mathrm{pH}$, dissolved oxygen and multiple nutrients [58]. In a study conducted in Augustow Canal in northeastern Poland, fungal species diversity and abundance were found to be dependent on the concentrations of total inorganic nitrogen, particulate organic carbon, sulphate and chloride ions and conductivity of the water [77]. Fungal communities in aquatic systems can act as bioindicators and the level of anthropogenic activity has been found 
to be strongly correlated with water quality and planktonic fungal community composition [78]. Environmental drivers (e.g., temperature, $\mathrm{pH}$, conductivity and nutrients), have been shown to play greater roles in structuring fungal leaf-litter decomposer communities than the spatial variables (latitude, longitude and altitude) in freshwater streams [79]. In our study, high-density residential and commercial land were the dominant land use types in the high urbanization locations; research and education institution areas and industrial land were the dominant land use types in medium urbanized locations; rivers and lakes, agricultural and public green land were the dominant land use types in low urbanization locations (Figure S1). Therefore, more riparian forests are in locations with medium and low urbanization as compared to high urbanization, which correlates to the results of fungal community composition observed. It is worth noting that plant-associated fungi were represented at high percentages in locations with medium and low urbanization.

In our study, the fungal community diversity varied between free water and colonized leaves therein and was profoundly influenced by season (winter versus summer). To a lesser extent, but nonetheless significant, the degree of urbanization in the canal environment also drove variation, due to the impact of land use on nutrient levels in the water.

\section{Conclusions}

The fungal diversity and composition in Suzhou canals was affected by both season and urbanization. The urbanization altered the fungal community composition but did not reduce the fungal diversity. The environmental drivers, and particularly temperature and nutrients, affected the fungal composition or fungal diversity. This study provides important information on the natural fungal flora relevant to the future restoration of urban canal systems facing multiple environmental challenges, such as global climate changes, urban heat island effects and eutrophication of water bodies. Further studies focusing on metagenomics and metatranscriptomics will enable the functional microbial communities in canals and their roles in the ecosystem function to be determined and build on baseline studies of diversity, such as that presented here for fungi inhabiting a gradient of urbanization across the extensive Suzhou canal system.

Supplementary Materials: The following are available online at http:/www.mdpi.com/2073-4441/12/7/1917/s1, Figure S1: Land use types in high (1-1 to 1-3), medium (2-1 to 2-3) and low (3-1 to 3-3) urbanization locations, Figure S2: Rarefaction curves generated with normalized sequence reads $(n=29,600)$ for water and leaf samples collected in winter and summer 2015, Figure S3: Redundancy analysis (RDA) showing correlation of nutrient parameters with fungal community composition in water $(A, C)$ and leaf samples $(B, D)$ collected from different sampling locations in winter and summer, Table S1: Range values of physico-chemical parameters of water samples collected from Suzhou canals in winter and summer.

Author Contributions: R.S., A.J.M. and Y.Z. conceived and designed the experiments; R.S. and T.Y. carried out the field sampling; T.Y. and Q.F. carried out the laboratory works; T.Y., X.W. and H.Z. provided support for fungal community analysis; T.Y. prepared the paper with the direction of his supervisors R.S., A.J.M. and Y.Z.; All the authors contributed to the revision of the paper. All authors have read and agreed to the published version of the manuscript.

Funding: We would like to thank Natural Science Foundation of the Jiangsu Higher Education Institutions of China (Grant No. 13KJB180022), Key Program Special Fund in Xi'an Jiaotong-Liverpool University (XJTLU; Grant No. KSF-E-20), Continuous Support Fund in XJTLU (Grant No. RDF-SP-88) and Natural Science Foundation of Jiangsu Province (Grant No. BK20171238) for funding support. Financial support to Tianma Yuan was provided through Postgraduate Research Scholarship (PGRS-13-03-09) awarded by Xi'an Jiaotong-Liverpool University (XJTLU).

Acknowledgments: We would like to thank Jianjun Wang for support and Shuang Liu for preparing of some of the figures. Thanks to Suzhou Planning Bureau for providing land use maps of Suzhou and Jing Lu for further analysis of the land use types.

Conflicts of Interest: The authors declare no conflict of interest.

\section{References}

1. Haines, J.R.; Herrmann, R.; Lee, K.; Cobanli, S.; Blaise, C. Microbial population analysis as a measure of ecosystem restoration. Bioremed. J. 2002, 6, 283-296. [CrossRef] 
2. Li, H.; Wang, X.; Liang, C.; Hao, Z.; Zhou, L.; Ma, S.; Li, X.; Yang, S.; Yao, F.; Jiang, Y. Abovegroundbelowground biodiversity linkages differ in early and late successional temperate forests. Sci. Rep. 2015, 5, 12234. [CrossRef] [PubMed]

3. Chen, S.; Yan, M.; Huang, T.; Zhang, H.; Liu, K.; Huang, X.; Li, N.; Miao, Y.; Sekar, R. Disentangling the drivers of microcystis decomposition: Metabolic profile and co-occurrence of bacterial community. Sci. Total Environ. 2020, 739, 140062. [CrossRef] [PubMed]

4. Paerl, H.W.; Dyble, J.; Moisander, P.H.; Noble, R.T.; Piehler, M.F.; Pinckney, J.L.; Steppe, T.F.; Twomey, L.; Valdes, L.M. Microbial indicators of aquatic ecosystem change: Current applications to eutrophication studies. FEMS Microbiol. Ecol. 2003, 46, 233-246. [CrossRef]

5. Duarte, S.; Bärlocher, F.; Trabulo, J.; Cássio, F.; Pascoal, C. Stream-dwelling fungal decomposer communities along a gradient of eutrophication unraveled by 454 pyrosequencing. Fungal Divers. 2014, 70, 127-148. [CrossRef]

6. Duarte, S.; Bärlocher, F.; Pascoal, C.; Cássio, F. Biogeography of aquatic hyphomycetes: Current knowledge and future perspectives. Fungal Ecol. 2016, 19, 169-181. [CrossRef]

7. Ittner, L.D.; Junghans, M.; Werner, I. Aquatic fungi: A disregarded trophic level in ecological risk assessment of organic fungicides. Front. Environ. Sci. 2018, 6, 105. [CrossRef]

8. Ingold, C.T. Aquatic hyphomycetes of decaying alder leaves. Trans. Br. Mycol. Soc. 1942, 25, 339-417. [CrossRef]

9. Bärlocher, F. Aquatic hyphomycetes in a changing environment. Fungal Ecol. 2016, 19, 14-27. [CrossRef]

10. Grossart, H.-P.; Rojas-Jimenez, K. Aquatic fungi: Targeting the forgotten in microbial ecology. Curr. Opin. Microbiol. 2016, 31, 140-145. [CrossRef]

11. Grossart, H.-P.; Van den Wyngaert, S.; Kagami, M.; Wurzbacher, C.; Cunliffe, M.; Rojas-Jimenez, K. Fungi in aquatic ecosystems. Nat. Rev. Microbiol. 2019, 17, 339-354. [CrossRef] [PubMed]

12. Duarte, S.; Pascoal, C.; Alves, A.; Correia, A.; Cassio, F. Assessing the dynamic of microbial communities during leaf decomposition in a low-order stream by microscopic and molecular techniques. Microbiol. Res. 2010, 165, 351-362. [CrossRef] [PubMed]

13. Delgado-Baquerizo, M.; Giaramida, L.; Reich, P.B.; Khachane, A.N.; Hamonts, K.; Edwards, C.; Lawton, L.A.; Singh, B.K.; Brophy, C. Lack of functional redundancy in the relationship between microbial diversity and ecosystem functioning. J. Ecol. 2016, 104, 936-946. [CrossRef]

14. Collier, K.J.; Clapcott, J.E.; Duggan, I.C.; Hamilton, D.P.; Hamer, M.; Young, R.G. Spatial variation of structural and functional indicators in a large new zealand river. River Res. Appl. 2013, 29, 1277-1290. [CrossRef]

15. Thompson, M.S.A.; Bankier, C.; Bell, T.; Dumbrell, A.J.; Gray, C.; Ledger, M.E.; Lehmann, K.; McKew, B.A.; Sayer, C.D.; Shelley, F.; et al. Gene-to-ecosystem impacts of a catastrophic pesticide spill: Testing a multilevel bioassessment approach in a river ecosystem. Freshw. Biol. 2016, 61, 2037-2050. [CrossRef]

16. Hill, B.H.; Perrotte, W.T. Microbial colonization, respiration, and breakdown of maple leaves along a stream-marsh continuum. Hydrobiologia 1995, 312, 11-16. [CrossRef]

17. Cummins, K.W. Structure and function of stream ecosystems. BioScience 1974, 24, 631-641. [CrossRef]

18. Suberkropp, K.; Klug, M.J. Fungi and bacteria associated with leaves during processing in a woodland steam. Ecology 1976, 57, 707-719. [CrossRef]

19. Das, M.; Royer, T.V.; Leff, L.G. Diversity of fungi, bacteria, and actinomycetes on leaves decomposing in a stream. Appl. Environ. Microbiol. 2007, 73, 756-767. [CrossRef]

20. Cuffney, T.F.; Wallace, J.B.; Lugthart, G.J. Experimental evidence quantifying the role of benthic invertebrates in organic matter dynamics of headwater streams. Freshw. Biol. 1990, 23, 281-299. [CrossRef]

21. Findlay, S.E.G.; Dye, S.; Kuehn, K.A. Microbial growth and nitrogen retention in litter of phragmites australis compared to typha angustifolia. Wetlands 2002, 22, 616-625. [CrossRef]

22. Kim, M.; Kim, W.-S.; Tripathi, B.M.; Adams, J. Distinct bacterial communities dominate tropical and temperate zone leaf litter. Microb. Ecol. 2014, 67, 837-848. [CrossRef] [PubMed]

23. Kominkova, D.; Kuehn, K.A.; Busing, N.; Steiner, D.; Gessner, M.O. Microbial biomass, growth, and respiration associated with submerged litter of phragmites australis decomposing in a littoral reed stand of a large lake. Aquat. Microb. Ecol. 2000, 22, 271-282. [CrossRef]

24. Johnston, S.R.; Boddy, L.; Weightman, A.J. Bacteria in decomposing wood and their interactions with wood-decay fungi. FEMS Microbiol. Ecol. 2016, 92, fiw179. [CrossRef] [PubMed] 
25. Soares, M.; Kritzberg, E.S.; Rousk, J. Labile carbon 'primes' fungal use of nitrogen from submerged leaf litter. FEMS Microbiol. Ecol. 2017, 93, fix110. [CrossRef] [PubMed]

26. Gossiaux, A.; Rollin, M.; Guérold, F.; Felten, V.; Laviale, M.; Bachelet, Q.; Poupin, P.; Chauvet, E.; Bec, A.; Danger, M. Temperature and nutrient effects on the relative importance of brown and green pathways for stream ecosystem functioning: A mesocosm approach. Freshw. Biol. 2020, 65, 1239-1255. [CrossRef]

27. Niyogi, D.K.; Hu, C.-Y.; Vessell, B.P. Response of stream fungi on decomposing leaves to experimental drying. Int. Rev. Hydrobiol. 2020, 105, 52-58. [CrossRef]

28. Liu, Z.; Lv, Y.; Ding, R.; Chen, X.; Pu, G. Light pollution changes the toxicological effects of cadmium on microbial community structure and function associated with leaf litter decomposition. Int. J. Mol. Sci. 2020, 21, 422. [CrossRef]

29. Seena, S.; Barlocher, F.; Sobral, O.; Gessner, M.O.; Dudgeon, D.; McKie, B.G.; Chauvet, E.; Boyero, L.; Ferreira, V.; Frainer, A.; et al. Biodiversity of leaf litter fungi in streams along a latitudinal gradient. Sci. Total Environ. 2019, 661, 306-315. [CrossRef]

30. Geraldes, P.; Pascoal, C.; Cássio, F. Effects of increased temperature and aquatic fungal diversity on litter decomposition. Fungal Ecol. 2012, 5, 734-740. [CrossRef]

31. Du, J.; Zhang, Y.; Yin, Y.; Zhang, J.; Ma, H.; Li, K.; Wan, N. Do environmental concentrations of zinc oxide nanoparticle pose ecotoxicological risk to aquatic fungi associated with leaf litter decomposition? Water Res. 2020, 178, 115840. [CrossRef] [PubMed]

32. Juvigny-Khenafou, N.P.D.; Zhang, Y.; Piggott, J.J.; Atkinson, D.; Matthaei, C.D.; Van Bael, S.A.; Wu, N. Anthropogenic stressors affect fungal more than bacterial communities in decaying leaf litter: A stream mesocosm experiment. Sci. Total Environ. 2020, 716, 135053. [CrossRef] [PubMed]

33. De Sherbinin, A.; Schiller, A.; Pulsipher, A. The vulnerability of global cities to climate hazards. Environ. Urban 2007, 19, 39-64. [CrossRef]

34. Du, N.; Ottens, H.; Sliuzas, R. Spatial impact of urban expansion on surface water bodies-A case study of wuhan, china. Landsc. Urban Plan. 2010, 94, 175-185. [CrossRef]

35. Yuan, T.; Vadde, K.K.; Tonkin, J.D.; Wang, J.; Lu, J.; Zhang, Z.; Zhang, Y.; McCarthy, A.J.; Sekar, R. Urbanization impacts the physicochemical characteristics and abundance of fecal markers and bacterial pathogens in surface water. Int. J. Environ. Res. Public Health 2019, 16, 1739. [CrossRef]

36. Hale, R.L.; Turnbull, L.; Earl, S.R.; Childers, D.L.; Grimm, N.B. Stormwater infrastructure controls runoff and dissolved material export from arid urban watersheds. Ecosystems 2014, 18, 62-75. [CrossRef]

37. Carrino-Kyker, S.R.; Swanson, A.K.; Burke, D.J. Changes in eukaryotic microbial communities of vernal pools along an urban-rural land use gradient. Aquat. Microb. Ecol. 2011, 62, 13-24. [CrossRef]

38. Iniguez-Armijos, C.; Rausche, S.; Cueva, A.; Sanchez-Rodriguez, A.; Espinosa, C.; Breuer, L. Shifts in leaf litter breakdown along a forest-pasture-urban gradient in andean streams. Ecol. Evol. 2016, 6, 4849-4865. [CrossRef]

39. Cunningham, S.C.; Mac Nally, R.; Baker, P.J.; Cavagnaro, T.R.; Beringer, J.; Thomson, J.R.; Thompson, R.M. Balancing the environmental benefits of reforestation in agricultural regions. Perspect. Plant Ecol. Evol. Syst. 2015, 17, 301-317. [CrossRef]

40. Emilson, C.E.; Kreutzweiser, D.P.; Gunn, J.M.; Mykytczuk, N.C.S. Effects of land use on the structure and function of leaf-litter microbial communities in boreal streams. Freshw. Biol. 2016, 61, 1049-1061. [CrossRef]

41. Rossi, F.; Mallet, C.; Portelli, C.; Donnadieu, F.; Bonnemoy, F.; Artigas, J. Stimulation or inhibition: Leaf microbial decomposition in streams subjected to complex chemical contamination. Sci. Total Environ. 2019, 648, 1371-1383. [CrossRef] [PubMed]

42. Rossi, F.; Pesce, S.; Mallet, C.; Margoum, C.; Chaumot, A.; Masson, M.; Artigas, J. Interactive effects of pesticides and nutrients on microbial communities responsible of litter decomposition in streams. Front. Microbiol. 2018, 9, 2437. [CrossRef] [PubMed]

43. Martínez, A.; Barros, J.; Gonçalves, A.L.; Canhoto, C. Salinisation effects on leaf litter decomposition in fresh waters: Does the ionic composition of salt matter? Freshw. Biol. 2020. [CrossRef]

44. Pu, G.; Zeng, D.; Mo, L.; Liao, J.; Chen, X.; Qiu, S.; Lv, Y. Artificial light at night alter the impact of arsenic on microbial decomposers and leaf litter decomposition in streams. Ecotoxicol. Environ. Saf. 2020, 191, 110014. [CrossRef]

45. Wang, L.; Shen, J.; Chung, C.K.L. City profile: Suzhou-A chinese city under transformation. Cities 2015, 44, 60-72. [CrossRef] 
46. Cao, Y.-1.; Wang, X.; Yin, C.-q.; Xu, W.-w.; Shi, W.; Qian, G.-r.; Xun, Z.-m. Inland vessels emission inventory and the emission characteristics of the beijing-hangzhou grand canal in jiangsu province. Process Saf. Environ. Prot. 2018, 113, 498-506. [CrossRef]

47. Zhuang, W.; Chen, Q.; Gao, X.; Zhou, F.; Wang, M.; Liu, Y. Characterization of surface sediments from the beijing-hangzhou grand canal (zaozhuang section), china: Assessment of beryllium enrichment, biological effect, and mobility. Environ. Sci. Pollut. Res. Int. 2016, 23, 13560-13568. [CrossRef]

48. Zhuang, W.; Liu, Y.; Chen, Q.; Wang, Q.; Zhou, F. A new index for assessing heavy metal contamination in sediments of the beijing-hangzhou grand canal (zaozhuang segment): A case study. Ecol. Indic. 2016, 69, 252-260. [CrossRef]

49. Reazin, C.; Morris, S.; Smith, J.E.; Cowan, A.D.; Jumpponen, A. Fires of differing intensities rapidly select distinct soil fungal communities in a northwest us ponderosa pine forest ecosystem. For. Ecol. Manag. 2016, 377, 118-127. [CrossRef]

50. French, K.E.; Tkacz, A.; Turnbull, L.A. Conversion of grassland to arable decreases microbial diversity and alters community composition. Appl. Soil Ecol. 2017, 110, 43-52. [CrossRef]

51. Dannemiller, K.C.; Reeves, D.; Bibby, K.; Yamamoto, N.; Peccia, J. Fungal high-throughput taxonomic identification tool for use with next-generation sequencing (fhitings). J. Basic Microbiol. 2014, 54, 315-321. [CrossRef] [PubMed]

52. McTaggart, L.R.; Copeland, J.K.; Surendra, A.; Wang, P.W.; Husain, S.; Coburn, B.; Guttman, D.S.; Kus, J.V. Mycobiome sequencing and analysis applied to fungal community profiling of the lower respiratory tract during fungal pathogenesis. Front. Microbiol. 2019, 10, 512. [CrossRef] [PubMed]

53. Vadde, K.; Wang, J.; Cao, L.; Yuan, T.; McCarthy, A.; Sekar, R. Assessment of water quality and identification of pollution risk locations in tiaoxi river (taihu watershed), China. Water 2018, 10, 183. [CrossRef]

54. Zhang, H.; Feng, J.; Chen, S.; Zhao, Z.; Li, B.; Wang, Y.; Jia, J.; Li, S.; Wang, Y.; Yan, M.; et al. Geographical patterns of nirs gene abundance and nirs-type denitrifying bacterial community associated with activated sludge from different wastewater treatment plants. Microb. Ecol. 2019, 77, 304-316. [CrossRef] [PubMed]

55. Vadde, K.K.; Feng, Q.; Wang, J.; McCarthy, A.J.; Sekar, R. Next-generation sequencing reveals fecal contamination and potentially pathogenic bacteria in a major inflow river of taihu lake. Environ. Pollut. 2019, 254, 113108. [CrossRef] [PubMed]

56. Ma, X.; Song, X.; Li, X.; Fu, S.; Li, M.; Liu, Y. Characterization of microbial communities in pilot-scale constructed wetlands with salicornia for treatment of marine aquaculture effluents. Archaea 2018, 2018, 7819840. [CrossRef] [PubMed]

57. Nguyen, M.T.H.D.; Thomas, T. Diversity, host-specificity and stability of sponge-associated fungal communities of co-occurring sponges. PeerJ 2018, 6, e4965. [CrossRef] [PubMed]

58. Ortiz-Vera, M.P.; Olchanheski, L.R.; Da Silva, E.G.; De Lima, F.R.; Martinez, L.R.D.P.R.; Sato, M.I.Z.; Jaffe, R.; Alves, R.; Ichiwaki, S.; Padilla, G.; et al. Influence of water quality on diversity and composition of fungal communities in a tropical river. Sci. Rep. 2018, 8, 14799. [CrossRef]

59. Miura, A.; Urabe, J. Spatial and seasonal changes in species diversity of epilithic fungi along environmental gradients of a river. Freshw. Biol. 2015, 60, 673-685. [CrossRef]

60. Bergfur, J.; Sundberg, C. Leaf-litter-associated fungi and bacteria along temporal and environmental gradients in boreal streams. Aquat. Microb. Ecol. 2014, 73, 225-234. [CrossRef]

61. Ferreira, V.; Canhoto, C. Effect of experimental and seasonal warming on litter decomposition in a temperate stream. Aquat. Sci. 2013, 76, 155-163. [CrossRef]

62. Ferreira, V.; Canhoto, C. Future increase in temperature may stimulate litter decomposition in temperate mountain streams: Evidence from a stream manipulation experiment. Freshw. Biol. 2015, 60, 881-892. [CrossRef]

63. Jabiol, J.; Gossiaux, A.; Lecerf, A.; Rota, T.; Guérold, F.; Danger, M.; Poupin, P.; Gilbert, F.; Chauvet, E. Variable temperature effects between heterotrophic stream processes and organisms. Freshw. Biol. 2020, 00, 1-20. [CrossRef]

64. Bärlocher, F.; Boddy, L. Aquatic fungal ecology-How does it differ from terrestrial? Fungal Ecol. 2016, 19, 5-13. [CrossRef]

65. Tolkkinen, M.; Mykra, H.; Annala, M.; Markkola, A.M.; Vuori, K.M.; Muotka, T. Multi-stressor impacts on fungal diversity and ecosystem functions in streams: Natural vs. Anthropogenic stress. Ecology 2015, 96, 672-683. [CrossRef] 
66. Reese, A.T.; Savage, A.; Youngsteadt, E.; McGuire, K.L.; Koling, A.; Watkins, O.; Frank, S.D.; Dunn, R.R. Urban stress is associated with variation in microbial species composition-But not richness-In manhattan. ISME J. 2015, 10, 751-760. [CrossRef]

67. Nikolcheva, L.G.; Bärlocher, F. Taxon-specific fungal primers reveal unexpectedly high diversity during leaf decomposition in a stream. Mycol. Prog. 2004, 3, 41-49. [CrossRef]

68. Seena, S.; Wynberg, N.; Bärlocher, F. Fungal diversity during leaf decomposition in a stream assessed through clone libraries. Fungal Divers. 2008, 30, 1-14.

69. Gleason, F.H.; Kagami, M.; Lefevre, E.; Sime-Ngando, T. The ecology of chytrids in aquatic ecosystems: Roles in food web dynamics. Fungal Biol. Rev. 2008, 22, 17-25. [CrossRef]

70. Wurzbacher, C.; Warthmann, N.; Bourne, E.; Attermeyer, K.; Allgaier, M.; Powell, J.R.; Detering, H.; Mbedi, S.; Grossart, H.-P.; Monaghan, M. High habitat-specificity in fungal communities in oligo-mesotrophic, temperate lake stechlin (north-east germany). MycoKeys 2016, 16, 17-44. [CrossRef]

71. Shearer, C.A.; Raja, H.A.; Miller, A.N.; Nelson, P.; Tanaka, K.; Hirayama, K.; Marvanova, L.; Hyde, K.D.; Zhang, Y. The molecular phylogeny of freshwater dothideomycetes. Stud. Mycol. 2009, 64, 145-153S144. [CrossRef] [PubMed]

72. Khomich, M.; Davey, M.L.; Kauserud, H.; Rasconi, S.; Andersen, T. Fungal communities in scandinavian lakes along a longitudinal gradient. Fungal Ecol. 2017, 27, 36-46. [CrossRef]

73. Kirk, P.M.; Cannon, P.F.; Minter, D.W.; Stalpers, J.A. Dictionary of the Fungi, 10th ed.; CABI: Wallingford, UK, 2008.

74. Nowicki, M.; Nowakowska, M.; Niezgoda, A.; Kozik, E. Alternaria black spot of crucifers: Symptoms, importance of disease, and perspectives of resistance breeding. Veg. Crops Res. Bull. 2012, 76, 5-19. [CrossRef]

75. Patriarca, A.; Fernández Pinto, V. Alternaria. In Reference Module in Food Science; Elsevier: Amsterdam, The Netherlands, 2018.

76. Gardeström, J.; Ermold, M.; Goedkoop, W.; McKie, B.G. Disturbance history influences stressor impacts: Effects of a fungicide and nutrients on microbial diversity and litter decomposition. Freshw. Biol. 2016, 61, 2171-2184. [CrossRef]

77. Cudowski, A.; Pietryczuk, A.; Hauschild, T. Aquatic fungi in relation to the physical and chemical parameters of water quality in the augustów canal. Fungal Ecol. 2015, 13, 193-204. [CrossRef]

78. Bai, Y.; Wang, Q.; Liao, K.; Jian, Z.; Zhao, C.; Qu, J. Fungal community as a bioindicator to reflect anthropogenic activities in a river ecosystem. Front. Microbiol. 2018, 9, 3152. [CrossRef]

79. Duarte, S.; Cássio, F.; Pascoal, C. Environmental drivers are more important for structuring fungal decomposer communities than the geographic distance between streams. Limnetica 2017, 36, 491-506. 